\title{
PARTISIPASI MASYARAKAT DALAM PROGRAM PEMBANGUNAN DI KELURAHAN ARJOSARI, KECAMATAN BLIMBING KOTA MALANG
}

\author{
Titik Poerwati \\ Dosen Prodi Perencanaan Wilayah dan Kota, Fak. Teknik Sipil dan Perencanaan, \\ ITN Malang e-mail: tpurwati@rocketmail.com \\ Daim Triwahyono \\ Dosen Prodi Arsitektur, Fak. Teknik Sipil dan Perencanaan, ITN Malang \\ e-mail: daimtri@gmail.com \\ Bambang Joko Wiji Utomo \\ Dosen Prodi Arsitektur, Fak. Teknik Sipil dan Perencanaan, ITN Malang \\ e-mail: bambangutomo92@gmail.com
}

\begin{abstract}
ABSTRAK
Sejak tahun 2009 di setiap kelurahan di Kota Malang mendapatkan dana bantuan dari pemerintah kota malang yang berupa dana hibah kepada masyarakat kelurahan melalui LPMK sebesar Rp. 500.000.000,- per tahun, dengan tujuan untuk pemberdayaan masyarakat kelurahan, serta untuk pembangunan fisik kelurahan yang belum tersentuh oleh pembangunan timgkat kota. Dengan adanya bantuan dana yang cukup besar untuk kelurahan dan harus dipertanggungjawabkan secara profesional maka LPMK dan kelurahan harus dapat mengalokasikan dana tersebut secara tepat sasaran dan benar-benar bermanfaat untuk pembangunan masyarakat kelurahan. Untuk hal tersebut kelurahan membutuhkan data kondisi masyarakat yang benar-benar akurat dan dapat di pertanggungjawabkan, baik data kondisi sosial ekonomi masyarakat maupun sarana prasarana yang di butuhkan oleh masyarakat. sehingga di butuhkan pendataan ulang kondisi sosial ekonomi maupun sarana dan prasarana kelurahan yang lebih valid dan realible. sehingga dapat di manfaatkan sebagai pedoman dalam penyusunan program pembangunan kelurahan baik yang di biayai oleh dana hibah kepada masyarakat maupun yang didanai oleh dana APBD pemerintah Kota Malang.
\end{abstract}

\section{Kata kunci: Partisipasi masyarakat, sosial ekonomi, program pembangunan}

\begin{abstract}
Since 2009, village's in Malang City have been get funding from the Malang City goverment be in the grants to community in village through LPMK amount of 500.000 .000 rupiah's every years, for intention empowering village communities, and physical development in the village which have not been touched by construction development city level. With the existence of substantial financial assistance for the village and must be professionals responsibility, LPMK and kelurahan must be able to allocate these funds with the right target and be useful for community development.
\end{abstract}

PAWON: Jurnal Arsitektur, Nomor 01 Volume III Bulan Januari-Juni Tahun 2020 ISSN 2597-7636 
For that needs data on conditions of community that accurate and accountable, like a data socio-economic conditions and infrastructure that community needed. Thats why needed re-registrationof social economic conditions and urban facilities and infrastructure that are more valid and realible.That it can be used as a guideline in program development village, those financed by grants or financed by goverment funds Malang city.

\section{Keywords : Community participation, socio-economic, development programs}

\section{PENDAHULUAN}

Sejauh ini ada banyak program pemerintah yang bertujuan untuk mengurangi kemiskinan baik dari pemerintah pusat, provinsi dan kabupaten / kota. Faktanya, karena jumlah program benar-benar tampaknya berjalan secara individual atau tidak ada sinergi antara program yang ada, walaupun tujuannya sama bagi masyarakat dalam pengurangan kemiskinan. Hasil program pengentasan kemiskinan yang telah diimplementasikan hingga saat ini belum membuahkan hasil yang menggembirakan. Banyak orang yang hidup di bawah garis kemiskinan masih cenderung meningkat jumlahnya.

Program-program tersebut, baik dalam proses perencanaan maupun implementasinya, ditangani langsung oleh masyarakat kelurahan, dimana masyarakatnya masih awan terhadap perencanaan dan implementasi pembangunan, sehingga yang terjadi adalah pembangunan yang bersifat sektoral dan individual, dikarenakan ada banyak kepentingan pribadi, pengurus di kelurahan, dan kurangnya pemahaman masyarakat terhadap tujuan dan proses pembangunan.

Kelurahan Arjosari salah satu kelurahan di Kecamatan Blimbing, Kota Malang yang masih belum memiliki buku pedoman pembangunan dalam bentuk rencana pembangunan kelurahan dalam bentuk rencana pembangunan jangka panjang, maupun rencana jangka menengah, sehingga pembangunan yang terjadi adalah pembangunan sektoral dan sporadis.

Dengan kondisi seperti itu, maka perlu memiliki rencana pembangunan di tingkat kelurahan yang terintegrasi antara perencanaan top-down dan perencanaan bottom-up sebagai aspirasi masyarakat di kelurahan. Untuk mendukung perencanaan pembangunan kelurahan yang optimal, perlu memiliki data yang cukup untuk mendukung proses perencanaan, dan memetakan potensi dan masalah masyarakat di kelurahan menjadi penting.

\section{TINJAUAN PUSTAKA}

Partisipasi masyarakat menurut Isbandi (2007: 27) adalah keikutsertaan masyarakat dalam proses pengidentifikasian masalah dan potensi yang ada

PAWON: Jurnal Arsitektur, Nomor 01 Volume III Bulan Januari-Juni, Tahun 2019, ISSN 2597-7636 
di masyarakat, pemilihan dan pengambilan keputusan tentang alternatif solusi untuk menangani masalah, pelaksanaan upaya mengatasi masalah, dan keterlibatan masyarakat dalam proses mengevaluasi perubahan yang terjadi.

\subsection{Pasrtisipasi sebagai Cara Dan Tujuan Menurut Oakley}

\subsubsection{Partisipasi sebagai cara}

1. Berimplikasi pada penggunaan partisipasi untuk mencapai tujuan atau sasaran yang telah ditetapkan sebelumnya.

2. Merupakan suatu Upaya pemanfaatan sumber daya yang ada untuk mencapai tujuan program atau proyek.

3. Lebih umum dalam program-program pemerintah, yang pertimbangan utamanya adalah untuk menggerakkan masyarakat dan melibatkan mereka dalam meningkatkan efisiensi sistem penyampaian.

4. Partisipasi umumnya jangka pendek.

5. Partisipasi sebagai cara merupakan bentuk pasif dari partisipasi

\subsubsection{Partisipasi sebagai tujuan}

1. Berupaya untuk memberdayakan rakyat untuk berpartisipasi dalam membangun mereka sendiri secara lebih berarti.

2. Berupaya untuk menjamin peningkatan peran rakyat dalam inisiatifinisiatif pembangunan.

3. Fokus pada peningkatan kemampuan rakyat untuk berpartisipasi bukan sekadar mencapai tujuan-tujuan proyek yang sudah ditetapkan sebelumnya.

4. Pandangan ini relatif kurang disukai oleh badan-badan pemerintah.

5. Pada prinsipnya LSM setuju dengan pandangan ini.

6. Partisipasi dianggap sebagai suatu proses jangka panjang.

7. Partisipasi sebagai tujuan relatif lebih aktif dan dinamis

\subsection{Partisipasi Masyarakat dalam Pemberdayaan Masyarakat}

Partisipasi masyarakat sering kali dianggap sebagai bagian yang tidak terlepas dalam upaya pemberdayaan masyarakat. Dengan melihat partisipasi sebagai kesatuan dalam proses pemberdayaan masyarakat, akan dapat diketahui bahwa akar perkembangan pemikiran tentang partisipasif dalam pembangunan akan terkait dengan diskursus komunitas. Dimana salah satu diskursus komunitas adalah asumsi bahwa masyarakat bukanlah sekumpulan orang yang bodoh, yang hanya bisa maju kalau mereka mendapatkan perintah belaka. Partisipasi masyrakat adalah keikutsertaan masyarakat dalam proses pengidentifikasian masalah dan potensi yang ada dimasyarakat, pemilihan dan pengambilan keputusan tentang alternatif solusi untuk menangani masalah, pelaksanaan upaya mengatasi masalah,

PAWON: Jurnal Arsitektur, Nomor 01 Volume III Bulan Januari-Juni Tahun 2020 ISSN 2597-7636 
keterlibatan masyarakat dalam proses mengevaluasi perubahan yang terjadi.

\subsection{Kelembagaan Masyarakat Kelurahan Arjosari}

Lembaga kemasyakatan yang ada di Kelurahan Arjosari antara lain :

1. Rukun Warga

: 5 buah

2. Rukun Tetangga : 34 buah

3. Lembaga Pemberdayaan Masyarakat Kelurahan (LPMK) yang diketuai oleh Bapak Drs. Sukatma

4. BKM dengan koordinator Ibu H.Toeti, SH

5. Gerdu Taskin

6. Karang Taruna yang diketuai oleh Saudara Eko Rahmat. P

7. Karang Wreda yang diketuai oleh Bpk. H. Yusuf Sutikno

8. FKPM (Forum Kemitraan Pemolisian Masyarakat) yang diketuai oleh Bpk. Drs. Supriyadi dan di wakili oleh Bpk. Luis (BAPINKAPTIMNAS POLRI).

Kelembagaan yang ada di Kelurahan Arjosari saling bersinergi dan bekerjasama guna meningkatkan kualitas masyarakat Arjosari dengan adanya program-program yang bermanfaat untuk masyarakat Kelurahan Arjosari.

\section{METODE PENELITIAN}

\subsection{Gambaran Fisik Kelurahan Arjosari}

Batas-batas Kelurahan Arjosari:

Sebelah Utara: Kelurahan Balearjosari, Kecamatan Blimbing.

Sebelah Timur: Kelurahan Tirtomoyo, Kecamatan Pakis, Kabupaten

Malang.

Sebelah Selatan: Kelurahan Polowijen, Kecamatan Blimbing.

Sebelah Barat: Kelurahan Polowijen, Kecamatan Blimbing.

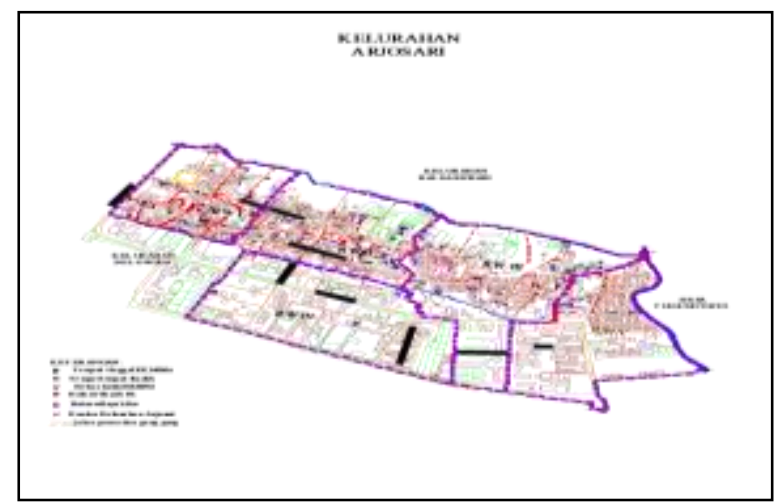

Gambar 1. Gambar Peta Kelurahan Arjosari

PAWON: Jurnal Arsitektur, Nomor 01 Volume III Bulan Januari-Juni, Tahun 2019, ISSN 2597-7636 


\subsection{Metode Pengumpulan Data}

Data dibedakan menjadi 2 (dua), yaitu: data primer dan data sekunder. Data primer adalah data yang diperoleh langsung di lapangan, sedangkan data sekunder adalah data yang melengkapi data primer, yaitu yang diperoleh dari instansi terkait berupa buku/dokumen/catatan yang diteliti.

\subsection{Metode Pelaksanaan}

Proses pendataan dilakukan dengan cara dibagi dalam 5 (lima) wilayah pendataan sesuai dengan wilayah ke RW an pada lokasi. masing-masing wilayah akan dilakukan oleh 2 orang surveyor, yang di bantu oleh perangkat RW dan satu tenaga dari kelurahan dengan alokasi waktu survai selama 6 hari kalender.dengan metoda survai sebagai berikut :

1. Langkah pertama adalah melakukan pengumpulan data sekunder yang di miliki oleh kelurahan.

2. Langkah kedua dilakukan pengumpulan data primer di lapangan yang di dahului dengan sosialisasi di setiap di setiap wilayah survai (sesuai dengan pembagian wilayah/5 wilayah $\mathrm{RW}$ ) yang di dampingi oleh seorang perangkat kelurahan.

3. Langkah berikutnya pengisian kuesioner oleh perangkat masing2 RW, yang dilanjutkan dengan peninjauan lapangan, mencocokkan antara data sekunder dengan data primer dilapangan.

4. Mendiskripsikan kondisi apa yang ada di lapangan.

5. Menyusun data termutakhir secara sistematis agar mudah di baca dan di mengerti oleh masyarakat setempat.

\section{HASIL DAN PEMBAHASAN}

\subsection{Kependudukan}

1. Mata pencaharian

Gambaran pola kehidupan suatu kelompok masyarakat dapat dilihat dari jenis- jenis mata pencahariaanya, pada umumnya penduduk Kelurahan Arjosari ini memiliki mata pencahariaan sebagai pedagang. Sedangkan mata pencahariaan yang lain meliputi, buruh bangunan, pensiunan, ABRI, swasta, pedagang, PNS, dan guru, adapun data tentang mata pencahariaan dapat dilihat pada tabel 1 .

Kondisi sosial, budaya dan ekonomi suatu daerah ini sangat bergantung pada pola mata pencaharian karena pertumbuhan suatu kawasan tidak lepas dari penduduk itu sendiri, dimana semakin kuat tingkat sosial dan ekonomi suatu kawasan akan mengakibatkan tingginya tingkat peradaban suatu kawasan. 
Tabel 1. Komposisi Penduduk menurut Mata Pencaharian

\begin{tabular}{|l|l|c|}
\hline No & \multicolumn{1}{|c|}{ Mata Pencahariaan } & Jumlah (Jiwa) \\
\hline 1 & Pengusaha Sedang & 12 \\
\hline 2 & Pengrajin Industri Kecil & 5 \\
\hline 3 & Buruh Industri & 274 \\
\hline 4 & Buruh Bangunan & 511 \\
\hline 5 & Perkebunan & - \\
\hline 6 & Pedagang & 757 \\
\hline 7 & Jasa Pengangkutan & 385 \\
\hline 8 & PNS & 442 \\
\hline 9 & TNI/Polri & 32 \\
\hline 10 & Petani & 30 \\
\hline 11 & Buruh Tani & 19 \\
\hline 12 & Dokter & 5 \\
\hline 13 & Montir & 76 \\
\hline 14 & Lain-lain & $\mathbf{2 . 7 0 1}$ \\
\hline \multicolumn{2}{|l|}{ Jumlah Total } & \\
\hline
\end{tabular}

Sumber Monografi Kelurahan Arjosari Tahun 2016

2. Pendidkan

Tabel 2. Komposisi Penduduk menurut Pendidikan

\begin{tabular}{|c|l|c|}
\hline No. & \multicolumn{1}{|c|}{ Jenjang Pendidikan } & Jumlah (Jiwa) \\
\hline 1. & TK/ PAUD & 675 \\
\hline 2. & Tidak Sekolah & 53 \\
\hline 3. & Putus Sekolah & 16 \\
\hline 4. & SD & 2.370 \\
\hline 5. & SLTP & 1.979 \\
\hline 6. & SMA/SMK/MU & 2.340 \\
\hline 7. & D1/D3 & 60 \\
\hline 8. & S1 & 165 \\
\hline 9. & S2 & 35 \\
\hline 10. & S3 & - \\
\hline 11. & Dll. Jumlah & - \\
\hline & \multicolumn{2}{|c|}{} \\
\hline
\end{tabular}

Sumber Monografi Kelurahan Arjosari Tahun 2016

\subsection{Permasalahan Ekonomi}

1. Pos Daya Ekonomi

a. Fungsi dan Peranan

PAWON: Jurnal Arsitektur, Nomor 01 Volume III Bulan Januari-Juni, Tahun 2019, ISSN 2597-7636 
Fungsi

Ada 8 (delapan) fungsi pemberdayaan yang menjadi konsep pergerakan posdaya yakni keagamaan, kebudayaan, cinta kasih, perlindungan, reproduksi, pendidikan, ekonomi, dan lingkungan hidup.

Peranan

Peranan Pos pembardaya keluarga (Posdaya) bagi masyarakat, adalah sebagai berikut :

- Sebagai sarana peningktan ekonomi keluarga

- Sebagai pelayanan pengembangan keluarga secara berkelanjutan, dalam berbagai bidang, terutama agama, kesehatan, ketahanan pangan, pendidikan, kewirausahan dan perekonomian keluarga.

b. Jumlah

Jumlah Pos Daya Ekonomi masyarakat di Kelurahan Arjosari sebanyak 1 kelompok yang terdiri 2 wilayah dan 8 kelompok kecil.

c. Lokasi

Lokasi beradanya Pos Daya Ekonomi masyarakat di Kelurahan Arjosari berada di RT 01 / RW 02

2. Kegiatan Ekonomi.

a. Jenis Kegiatan ekonomi

Jenis kegiatan yang digeluti ada pengrajin satelkop

b. Jumlah Kegiatan ekonomi

Terdiri dari 8 kelompok pengrajin yang berada di RT 01 /RW 05

\subsection{Rumusan Permasalah Kelurahan dan usulan pemecahan}

Tabel 3. Rumusan Masalah dan Solusi Pemecahannya

\begin{tabular}{|c|l|l|}
\hline No. & \multicolumn{1}{|c|}{ Permasalahan } & \multicolumn{1}{|c|}{ Solusi } \\
\hline 1 & Kurangnya & Berdasarkan UURI No. 4/1992 (tentang \\
. & drainase / & Perumahan dan Permukiman) dapat diketahui \\
& pembuanga & berbagai jenis prasarana permukiman seperti \\
& n air kotor & yang tercantum dalam Pasal 5 -7, maka \\
pada & pengelolaan drainase sangat dianjurkan \\
& pemukiman \\
penduduk. & \\
\hline
\end{tabular}




\begin{tabular}{|c|l|l|}
\hline No. & \multicolumn{1}{|c|}{ Permasalahan } & \multicolumn{1}{c|}{ Solusi } \\
\hline 2 & $\begin{array}{l}\text { Kurangnya } \\
\text { RTH/Ruang } \\
\text { Terbuka Hijau } \\
\text { pada kelurahan } \\
\text { Arjosari }\end{array}$ & $\begin{array}{l}\text { Ruang Terbuka Hijau (RTH) selain berfungsi } \\
\text { sebagai tempat komunal sosial di lingkungan } \\
\text { permukiman, kemudian sebagai tempat sarana } \\
\text { ruang terbuka hijau sebagai pengembangan } \\
\text { lingkungan yang sehat dan bersih oleh karena } \\
\text { itu RTH sangat penting mengingat di Kelurahan } \\
\text { Arjosari sangat minim Ruang Terbuka Hijau } \\
\text { (RTH) agar berupaya mengoptimalkan lahan- }\end{array}$ \\
\hline 3 & Masalah Sampah \\
\hline $\begin{array}{l}\text { Wilayah dusun kurang memiliki bak } \\
\text { pembuangan sampah sebagai pemecahan } \\
\text { masalah sampah. Sehingga ke depan } \\
\text { direncanakan adanya pembangunan bak-bak } \\
\text { sampah di sekitar areal pemukiman penduduk } \\
\text { untuk memenuhi kebutuhan pengelolaan } \\
\text { sampah, dan sarana penyadaran masyarakat } \\
\text { untuk senantiasa mengembangkan pola hidup } \\
\text { sehat. }\end{array}$ \\
\hline 5
\end{tabular}

PAWON: Jurnal Arsitektur, Nomor 01 Volume III Bulan Januari-Juni, Tahun 2019, ISSN 2597-7636 


\begin{tabular}{|l|c|ll|}
\hline No. & Permasalahan & \multicolumn{2}{|c|}{ Solusi } \\
\hline 6. & Prasarana Jalan & $\begin{array}{l}\text { Masih ada beberapa jalan yang mengalami } \\
\text { kerusakan pada kelurahan Arjosari agar } \\
\text { diperbaiki sehingga tidak menimbulkan } \\
\text { kerusakan vang begitu parah. }\end{array}$ \\
\hline
\end{tabular}

Sumber: Hasil Analisis dan Perbandingan, 2016

\section{KESIMPULAN}

Masalah sosial dalam kehidupan masyarakat sangatlah banyak akan tetapi sebenarnya terdapat 3 (tiga) faktor utama yang menyebabkan timbulnya masalah sosial, yang diantaranya seperti berikut ini:

\section{Faktor Ekonomi}

Masalah dalam ekonomi biasanya berupa masalah pengangguran, kemiskinan dan lain-lain. Dalam masalah ini biasanya yang harus bertanggung jawab adalah pemerintah, karena pemerintah kurang menyediakan lapangan kerja bagi masyarakat. Jika masyarakat mengalami permasalahan ini akan mengakibatkan sangat rentannya anggota masyarakat untuk melakukan tindakan krriminalitas dan kekurangan ekonomi dapat dijadikan suatu alasan atau pembenaran dalam melakukan tindakan tersebut. Faktor ekonomi juga dapat dijadikan sebagai acuan maju atau tidaknya suatu negara serta faktor ekonomi dapat mempengaruhi masalah sosial pada aspek prikologis dan biologis masyarakat.

\section{Faktor Budaya}

Faktor ini maksudnya kebudayaan yang semakin berkembang pada masyarakat akan mempunyai peran yang dapat memicu timbulnya masalah sosial. Faktor ini harus mendapat perhatian secara serius karena kebudaya pada suatu negara dapat mencerminkan kebiasaan masyarakatnya. Dengan mempelajari atau mendalami pendidikan agama mungkin dapat mencegah, menyadarkan ataupun menyaring budaya asing yang masuk.

\section{Faktor Psikologis}

Selain faktor diatas ada juga faktor psikologis, masalah seperti ini dapat muncul jika psikologis suatu masyarakat sangat lemah. Faktor psikologis juga dapat juga muncul jika beban hidup yang berat yang dirasakan oleh masyarakat khususnya yang ada di daerah perkotaan, pekerjaaan yang menumpuk sehingga menimbulkan stress lalu dapat menimbulkan luapan emosi yang nantinya dapat memicu konflik antar anggota masyarakat. 


\section{DAFTAR PUSTAKA}

Isbandi Rukminto Adi. (2007). Perencanaan Partisipatoris Berbasis Aset Komunitas: dari Pemikiran Menuju Penerapan. Depok: FISIP UI Press.

Isbandi Rukminto Adi. Revisi 2012. Pemberdayaan Masyarakat dan Partisipasi Masyarakat. Jakarta: Raja Grafindo Persada. Hal $227,228,229,230,231$

Jim Ife .2006. Community Development. Yogyakarta: Pustaka Belajar. Hal $294,295296,297$

Finna Rizqinna. 2010. Partisipasi Masyarakat. www.lontar.ui.id. Hal 14 